\title{
A Simple Operating Strategy of Small-Scale Battery Energy Storages for Energy Arbitrage under Dynamic Pricing Tariffs
}

\author{
Enrico Telaretti *, Mariano Ippolito and Luigi Dusonchet \\ Received: 9 October 2015; Accepted: 16 December 2015; Published: 25 December 2015 \\ Academic Editor: William Holderbaum \\ Department of Energy, Information Engineering and Mathematical Models, University of Palermo, \\ Viale delle Scienze, 90128 Palermo, Italy; ippolito@dieet.unipa.it (M.I.); dusonchet@dieet.unipa.it (L.D.) \\ * Correspondence: telaretti@dieet.unipa.it; Tel.: +39-091-238-602-62; Fax: +39-091-488-452
}

\begin{abstract}
Price arbitrage involves taking advantage of an electricity price difference, storing electricity during low-prices times, and selling it back to the grid during high-prices periods. This strategy can be exploited by customers in presence of dynamic pricing schemes, such as hourly electricity prices, where the customer electricity cost may vary at any hour of day, and power consumption can be managed in a more flexible and economical manner, taking advantage of the price differential. Instead of modifying their energy consumption, customers can install storage systems to reduce their electricity bill, shifting the energy consumption from on-peak to off-peak hours. This paper develops a detailed storage model linking together technical, economic and electricity market parameters. The proposed operating strategy aims to maximize the profit of the storage owner (electricity customer) under simplifying assumptions, by determining the optimal charge/discharge schedule. The model can be applied to several kinds of storages, although the simulations refer to three kinds of batteries: lead-acid, lithium-ion (Li-ion) and sodium-sulfur (NaS) batteries. Unlike literature reviews, often requiring an estimate of the end-user load profile, the proposed operation strategy is able to properly identify the battery-charging schedule, relying only on the hourly price profile, regardless of the specific facility's consumption, thanks to some simplifying assumptions in the sizing and the operation of the battery. This could be particularly useful when the customer load profile cannot be scheduled with sufficient reliability, because of the uncertainty inherent in load forecasting. The motivation behind this research is that storage devices can help to lower the average electricity prices, increasing flexibility and fostering the integration of renewable sources into the power system.
\end{abstract}

Keywords: price arbitrage; battery energy storage system; optimal operation; hourly electricity prices; energy management

\section{Introduction}

Electricity customers will face significant challenges in the near future due to the most recent developments in the energy market sector. These changes have been mainly driven by the increasing penetration of renewable and distributed energy sources in the power system, which can positively contribute to a reduction of $\mathrm{CO}_{2}$ emissions. The diffusion of renewable sources has been made possible thanks to the introduction of support policies, such as those put in place for the photovoltaic (PV) and wind technology [1-4]. Clearly, the transition from the current centralized electricity market structure towards a decentralized market model will require major investments in the electricity grid infrastructure, in order to ensure an adequate level of quality and reliability of the energy supply. 
In the spot markets, the electricity price varies stochastically from one day to the next and systematically between seasons. The marginal cost of producing energy has become much more volatile in the last decade, mainly due to the recent moves toward competitive liberalized markets. Indeed, the competition among actors has increased the range of variability in electricity prices, expanding the difference between on-peak and off-peak prices. Normally, electricity users are not exposed to these fluctuations but pay a constant price. In an attempt to reduce demand peaks, several utilities are moving from a conventional fixed-rate pricing scheme to new market-based models, where the electricity cost is free to fluctuate depending on the balance between supply and demand. Such dynamic pricing schemes reflect the prices of the wholesale market and are able to lower demand peaks and the volatility of the wholesale prices [5]. A first example of dynamic pricing tariff is time-of-use (TOU) pricing, which provides two or three periods of different electricity price (generally "on-peak", "mid-peak" and "off-peak" prices), depending on the hour of day. Electricity users are advised in advance about electricity prices that are not normally modified more than once or twice per year. A more flexible electricity-pricing scheme is real-time pricing $(R T P)$, for which the retail electricity price closely reflects the wholesale energy price. In this case, customer electricity prices can vary hourly depending on the wholesale market and electricity users can manage their power consumption in a more flexible and economical manner, taking advantage of the price differential. The real-time prices can be notified to electricity customers with different timing, depending on the specific utility's RTP program. For example, with Ameren's RTP program (an Illinois' Electric Utility), hourly prices for the next day are set the night before and are communicated to customers so they can modify their power consumption in advance. Differently, with ComEd's RTP program (another Illinois' Electric Utility), hourly prices are based on the average of the twelve five-minute prices for each hour, and electricity users are notified in real-time, only when the hour has passed. Later on in this article, the RTP prices will be considered as day-ahead hourly prices, so electricity customers are advised a day before and can modify their power consumption accordingly.

The highly volatile behavior of the electricity price can be exploited by using an energy storage device in order to capture the price differential. Indeed, if an electricity customer is charged at an hourly-dependent rate, a storage system can be adopted with the aim to shift portions of consumption to different hours than those where they actually occur. The electricity is simply stored when it is inexpensive and resold back to the grid at a higher price [6,7].

The object of this article is to analyze, develop and demonstrate a charge/discharge scheduling method able to maximize the arbitrage benefit of a storage system, subject to technical constraints. The storage system is described by means of its performance parameters, such as the charge and generation capacity, the charge/discharge efficiency, the rated charge/discharge rate, the depth-of-discharge $(D O D)$, etc., which are sufficient to evaluate the arbitrage potential of a storage system. The scheduling strategy is based on the definition of an objective function, able to maximize the arbitrage benefit of the storage owner subject to technical constraints, allowing the battery to be charged/discharged at different $D O D$, as further detailed in Section 4 . The developed model is valid for any kind of storage, although the simulations refer to a lead-acid, a lithium-ion (Li-ion) and a sodium-sulfur $(\mathrm{NaS})$ battery. Test results show that the proposed operating strategy is effective to maximize the profit for the customer. Unlike the studies reported in the literature, often requiring an estimate of the end-user load profile, the proposed operation strategy is able to properly identify, for each daily period, the charge/discharge hours relying only on the hourly spot market price profile, regardless of the specific facility's consumption. This is made possible thanks to some simplifying assumptions in the sizing and the operation of the battery energy storage system (BESS), as further details in Section 3. This could be particularly useful when the customer load profile cannot be scheduled with sufficient reliability because of the uncertainty inherent in load forecasting. In these cases, identifying a BESS operating strategy that does not depend on the user's power profile can be an important task, since the deviation of the scheduled power profile from the effective one could 
affect the results obtained using more complete methods. Furthermore, the proposed management strategy requires a low computational burden and can be implemented in simple and available software, for instance in a spreadsheet, representing a friendly but effective instrument to optimize the charge/discharge schedule of a storage device.

The next section summarizes existing literature on the topic of optimal operation of storage systems. In Section 3, the customer energy system used in this paper is briefly described and the basic operational assumptions are outlined. In Section 4, the problem formulation is provided, showing the objective function to be maximized and defining the constraint equations. In Section 5, a case study is presented and the technical and economic parameters for each storage device are provided. Section 6 shows the simulation results and some important remarks about the operating schedule of the storage devices. Finally, Section 7 summarizes the conclusion of the work.

\section{Current Literature}

Traditionally, most of the studies address the optimal operation of a storage system based on linear programming [8-11], nonlinear programming [12], dynamic programming [13-16] and multipass iteration particle swarm optimization approach [17]. Other charge/discharge strategies are described in [18-25].

\subsection{Linear and Nonlinear Programming}

In [8], the authors study the optimal operation of an energy storage unit installed in a small power producing facility using a conventional linear programming technique. In [9], the authors determine the optimal charge/discharge schedule by using a linear optimization model of the battery systems (based on Li-ion and lead-acid technology) for arbitrage accommodation. They found that the cost and the efficiency of the storage systems have the highest impact on simulation results. The developed model is linear and can thus be solved without much computational effort. Bradbury et al. [10] studied seven real-time US electricity markets and 14 different storage technologies, finding that the optimal profit-maximizing size of a storage device (i.e., hours of energy storage) depends largely on its technological characteristics (round-trip charge/discharge efficiency and self-discharge), rather than the magnitude of market price volatility, which instead increases internal rate of return (IRR). The arbitrage benefit is maximized using a simple linear programming, subject to technical constraints. Graves et al. [11] emphasize the fact that using average peak and off-peak prices does not account for the variability in prices and thus leading to significant errors in the optimal management strategy. They also discuss the use of a linear programming for determining the optimal operation strategy.

In [12], the authors present an optimal operation strategy of BESSs to the real-time electricity price in order to achieve maximum profits of the BESS. The algorithm is based on a sequential quadratic programming method as to maximize the profits for the customer. The strategy is promising although operating and maintenance costs of the BESS are not taken into account.

\subsection{Dynamic Programming}

Linear programming is often considered to be too inflexible, as it typically does not capture the stochastic nature of load profiles. In order to overcome the restriction, dynamic programming methods are employed to capture the uncertainties in load profiles and electricity prices [13]. The algorithm developed in [14] is a multipass dynamic programming that ensures the minimization of the electricity bill for a given battery capacity, while reducing stress on the battery and prolonging battery life. In [15], the authors address the problem of organizing home energy storage purchases as a Markov decision process, showing that there exists a threshold-based stationary cost-minimizing policy. The battery is charged up to the threshold, when the battery level is below the threshold, and discharged when the level is above the threshold. The proposed strategy is interesting, even though the system cost is not considered. In [16], the authors propose a self-learning optimal operating 
control scheme based on adaptive dynamic programming for the residential energy system with batteries. The algorithm is effective in achieving minimization of the cost through neural network learning. The main feature of the proposed scheme is the ability of the continuous learning and adaptation to improve the performance during real-time operations under uncertain changes in the environment or new system configuration of the residential household.

\subsection{Other BESS Management Strategies}

In [17], a modified particle swarm optimization (PSO) algorithm (called multipass iteration PSO) is used to solve the optimal operating schedule of a BESS for an industrial TOU rate user with wind turbine generators. Thanks to the high computational efficiency, the algorithm can be used to evaluate the optimal operating policy of a BESS in real-time applications, based on the load condition of the user, the energy left in the BESS, and the output of wind turbines. In [18], the authors estimate the benefit of using energy storages for aggregate storage applications, such as energy price arbitrage, TOU energy cost reduction, ancillary services, and transmission upgrade deferral. The maximization of the arbitrage benefit is carried out by maximizing an objective function, under the assumption that the electricity prices are both dependent/independent on the battery operation. In [19], a simple methodology to charge/discharge a residential battery system for energy arbitrage in presence of TOU prices was described. The statistical variability of the household consumption was accounted through a Monte Carlo method. The economic feasibility of the storage system was determined in the context of the Australian retail electricity market, showing that, for various BESSs, the load shifting strategy can be profitable. In [20], the authors present an estimation of the economic feasibility of electricity storage in the west Danish power market, exploiting a simple operation strategy of the BESS in the spot market. The strategy includes two main conditions: (1) the price for buying must be less than the price for selling times the round trip efficiency (in order to ensure positive incomes) and (2) the amount of power bought in a given time period must equal the amount of power sold times the round trip efficiency (in order to ensure the balance of energy). Shcherbakova et al. (2014) [21] simulated the operation and resulting profits of small storage batteries (NaS and Li-ion) in South Korea using a charge/discharge strategy based on Hotelling rule. They concluded that neither technology generates a sufficient amount of arbitrage revenue to cover the battery's capital costs. Purvins and Summer [22] presented an optimal battery system management model in distribution grids for lithium-ion battery system used in stationary applications. The proposed approach is based on three management priorities, the first being the maximum utilization of renewable energy sources (RES) energy in distribution grids (preventing situations of reverse power flow at the distribution level), followed by efficient battery utilization (charging at off-peak prices and discharging at peak prices) and residual distribution grid demand smoothing. Finally, in [23,24], the authors evaluate the capacity of storage and active demand side management (DSM) to increase the self-consumed electricity in the residential sector, using a lead-acid battery. The operating strategy is based on self-consumption maximization, reducing the use of the grid and supplying the highest amount of energy from PV generation. In [25], the authors present a home energy management system model that uses a heuristic algorithm to manage and control home appliances based on a combination of energy pricing models including TOU and RTP tariffs. The algorithm aims to minimize overall usage and cost of energy without significantly degrading consumer comfort.

\section{Energy System Description and Operational Assumptions}

The customer energy system consists of a passive user (end-user), interconnected to a storage system through a bidirectional converter, as depicted in Figure 1. The bidirectional converter consists of a rectifier AC/DC (the battery charger) and an inverter DC/AC [26,27]. The battery system is handled in order to ensure an economic benefit for the customer, exploiting a load shifting strategy. Since the system marginal price (SMP) value is available one day ahead and it is defined each hour, the electricity prices are considered as hourly-dependent prices, where each hour of the day has a 
different electricity price. The reference period used in the study is one day, i.e., the battery operation is defined starting from a vector of 24 elements as input data.

Three different operating modes are considered for the storage system: charging mode, activated when the electricity prices are low; standby mode, in which the power grid supplies directly the end-user without contribution of the storage; and discharging mode, activated when the electricity prices are high, where part of the load is supplied from the battery.

The following assumptions have been made:

- The end-user is allowed to buy the consumed energy at an hourly tariff (RTP tariff), defined by the utility on a daily basis. The RTP tariffs are assumed to be proportional to the SMP values, by applying a percentage increase to incorporate the benefit for the utility and taxes (electricity tax and value added tax (VAT)).

- The power flow is always directed from the grid to the load. The stored energy can only be used by the customer for load compensation and cannot be sold to the utility.

- The hourly electricity prices are known in advance in a finite horizon setting (daily period) and the use of the storage device does not influence the prices of electricity in the energy market (small price taking storage devices). Predictions about future electricity rates are not part of this work since the aim is to show results based upon the current electricity prices.

- Battery self-discharge is disregarded.

- Battery capacity is assumed constant throughout the battery life, without degradation.

- The common frictions during battery operation are accounted for by incorporating imperfect charging and discharging efficiency;

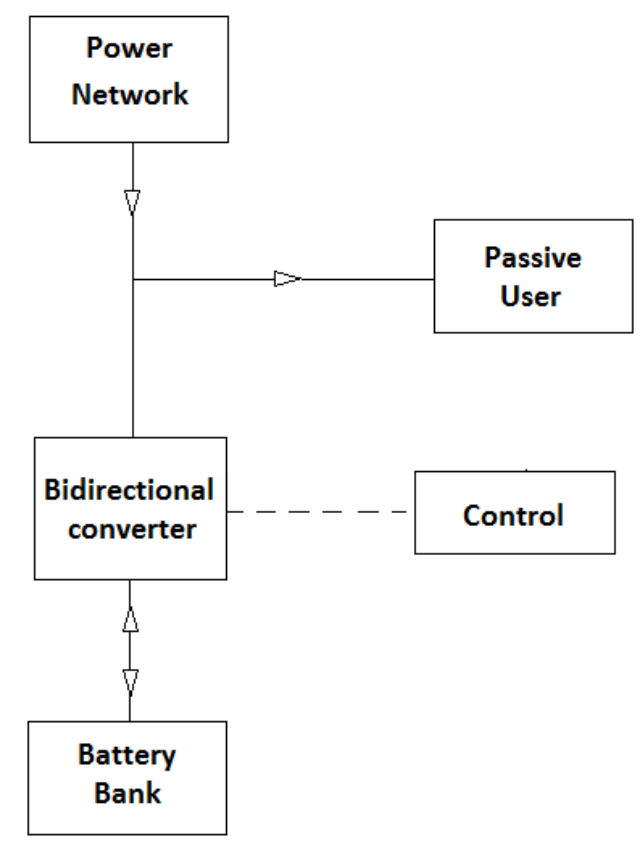

Figure 1. Grid-connected customer energy system operating in parallel with the storage system.

- The charge/discharge rate of the battery is assumed constant and equal to the rated power capacity of the device. Doing so, the storage charge/discharge constraints are automatically satisfied (i.e., the energy charged/discharged into the battery at any time $t$ cannot be more than the rated power capacity of the device). It is worth noting that both the battery capacity and the battery life are influenced by the charging rate. Indeed, at very high rates the capacity cell and the battery life are reduced. Fast charging may also have negative consequences on the battery efficiency [28]. Therefore, the use of a battery at constant charge/discharge rate helps 
to prolong the battery life, to preserve the rated capacity and to keep the battery efficiency at appropriate values.

- The charging time is assumed equal to the discharging time, in each operating cycle. According to the last two mentioned hypotheses, the battery returns to the initial state-of-charge (SOC) at the end of each operating cycle. Such an operation means that the battery energy constraints are automatically satisfied (i.e., the storage level of the battery cannot be more than the rated energy capacity of the device).

- The $D O D$ of the battery can take different discrete states, depending on the value of the objective function.

- The storage capacity is assumed equal to the facilities' energy consumption during peak times (i.e., the hours where electricity prices are the highest) on the day of the year of lowest consumption [29]. In other words, the battery is sized so that it can supply the entire customer load during peak price hours, on the day of the year of lowest consumption, and only a portion of the customer's load on the other days. The choice of the storage capacity is driven by a trade-off between gaining more arbitrage savings during days with relatively high peak loads and wasting idle capacity during days with low peak loads. Among all the possible solutions, the one that ensures the minimum upfront investment cost for the storage owner has been chosen. The aim of this article is to identify a battery operating strategy able to maximize the profit of the storage owner (under the considered assumptions), without attempting to identify the optimal BESS capacity. In other words, the battery has been sized according to a criterion of minimum cost, which is not necessarily the optimal one. As a consequence of this statement, the BESS can be operated regardless of the specific facility's load profile and the power flow is always directed from the grid to the load, without selling to the utility.

\section{Problem Formulation}

\subsection{Preliminary Considerations}

The optimal operating strategy of the storage device is able to uniquely determine the daily charge/discharge intervals so as to maximize the economic saving for the customer. Figure 2 shows typical daily profiles of SMP (the national single price of the Italian day-ahead market) for a reference weekly period (from 31 March to 6 April 2014) [30]. The profiles clearly show a first couple of $\mathrm{min} / \mathrm{max}$ prices in the first semi-daily period and a second couple in the second half of the day. The battery thus will be charged only once a day, twice a day or it will remain idle, depending on the maximization of the objective function. Since the RTP tariffs are assumed to be proportional to the SMP values, hereinafter will be referred as RTP prices. It is worth noting that weekdays RTP values have a first price peak at about 8:00-10:00 a.m. and a second peak at 8:00-9:00 p.m. Differently, Sunday only retains the second peak at 9:00 p.m. As a result, we can expect that the BESS could be charged two times on weekdays (including Saturday), only one time on Sunday.

Since the battery can be charged/discharged at different $D O D$, the algorithm calculates the moving average (MA) of RTP prices (MA RTP) corresponding to each charge/discharge time, $d$, where $d$ is a discrete variable denoting the charge/discharge time of the battery (corresponding to different $D O D$ values). For example, assuming that the charge/discharge time, $d$, can take $D$ different discrete values, the algorithm calculates $D$ daily profiles of $M A R T P$ prices, for each day of the year, $i$ :

$$
\operatorname{MA}_{R T P_{i, d}}(h)=\sum_{n=h}^{h+d-1} \operatorname{RTP}(n) / d h=1, \ldots, 24-d+1 ; d=1, \ldots, D ; i=1, \ldots, 365
$$

where $d$ is an index denoting the charge/discharge time of the battery, $i$ is an index denoting the day of the year, $h$ is an index denoting the hour of the day, $D$ is the maximum charge/discharge time of the battery (corresponding to the maximum DOD) and $M A_{R T P_{i, d}}(h)$ is the $M A$ of $R T P$ prices in hour 
$h$, corresponding to the charge/discharge time $d$ in the day $i$. In the following, all equations will be referred to a generic day $i$, and the variability of the index over the year will be omitted.

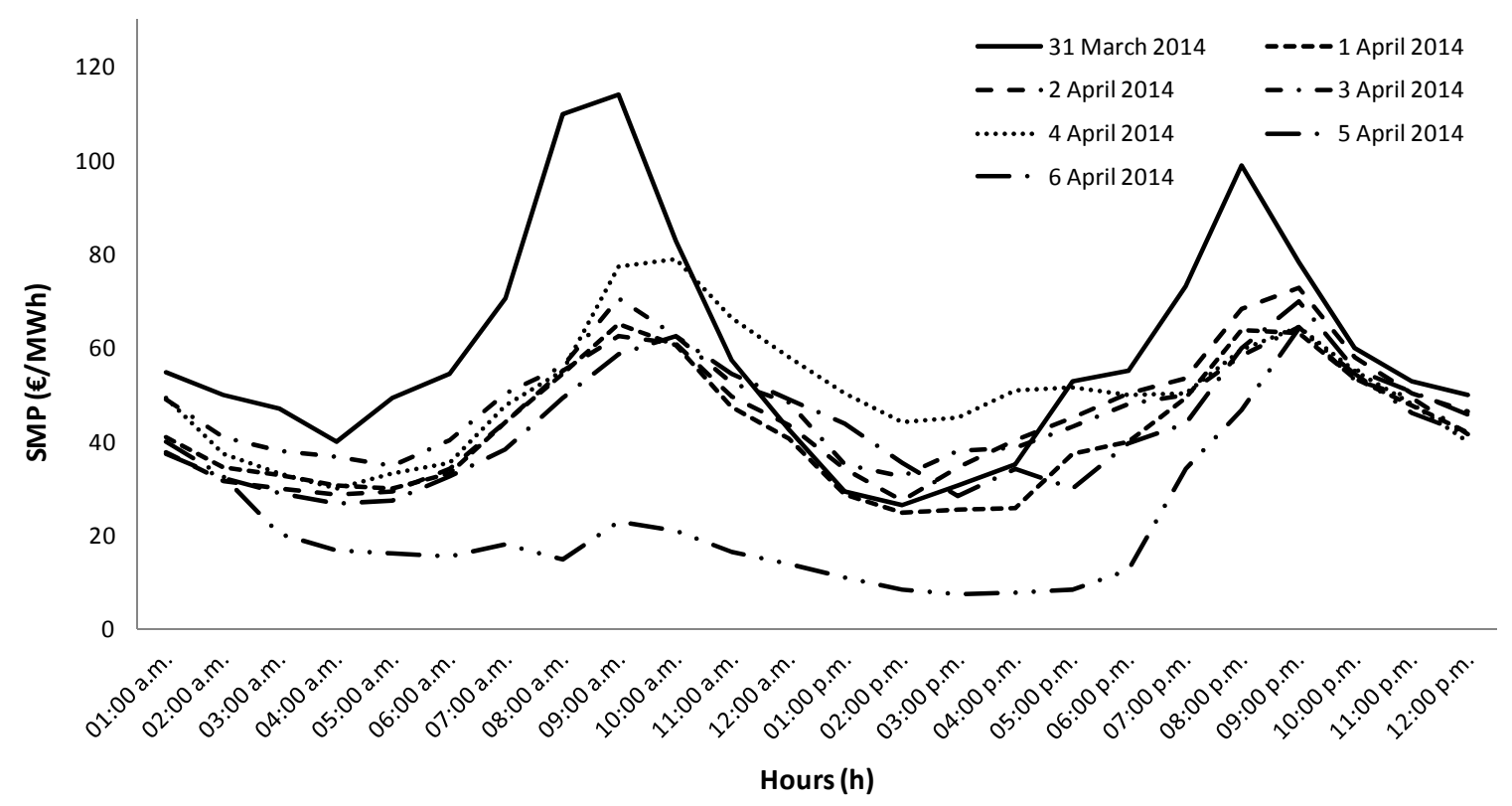

Figure 2. System marginal price (SMP) for the weekly period from 31 March to 6 April 2014.

Since the charge/discharge rate of the battery, $P_{B E S S}$, is assumed constant, the following relation exists between the DOD and the discharged time, $d$ :

$$
D O D=\frac{E_{B E S S}}{C a p}=\frac{P_{B E S S} \cdot d}{P_{B E S S} \cdot D_{\max }}=\frac{d}{D_{\max }}
$$

where $E_{B E S S}$ is the energy discharged from the storage device, Cap is the rated energy capacity of the BESS, and $D_{\max }$ is the maximum theoretical discharging time of the battery, corresponding to a full discharge (this is a theoretical discharging value, since the battery can never fully discharge).

Since the battery can be charged once or twice a day, depending on the maximization of the objective function, the algorithm takes into account two MA RTP profiles for each charge/discharge time $d$, the first referred to a daily period, the second to a semi-daily period. In other words, the algorithm scans both the daily and the semi-daily MA RTP profiles, with the aim of verifying whether the maximum of the objective function corresponds to only one cycle or to two cycles per day. Figure $3 \mathrm{a}$, b shows the daily profile of MA RTP related to a daily period or to a semi-daily period, together with the daily/semi-daily average value, respectively:

$$
\begin{gathered}
\operatorname{Aver}_{M A_{i, d}}=\sum_{h=1}^{24-d+1} M A_{R T P_{i, d}}(h) /(24-d+1) ; d=1, \ldots, D \\
\left\{\begin{array}{c}
\operatorname{Aver}_{M A_{i, d}^{(1)}}=\sum_{h=1}^{12} M A_{R T P_{i, d}}(h) / 12 \\
\operatorname{Aver}_{M A_{i, d}^{(2)}}=\sum_{h=(12-d+1)}^{(24-d+1)} M A_{R T P_{i, d}}(h) / 12
\end{array}\right.
\end{gathered}
$$


where $\operatorname{Aver}_{M A_{i, d}}$ is the daily average value of the $M A R T P$ profile and $\operatorname{Aver}_{M A_{i, d}^{(k)}}$ is the semi-daily average value of the MARTP profile (in the semi-daily period $k$ of the day $i$, with $k=1,2$ ). Figure $3 \mathrm{a}, \mathrm{b}$ also shows the $\mathrm{min} / \mathrm{max}$ values of MA RTP profiles in the daily/semi-daily period:

$$
\begin{gathered}
M A_{R T P_{i, d, \text { min }}}, M A_{R T P_{i, d, \text { max }}} ; d=1, \ldots, D \\
M A_{R T P_{i, d, \text { min }}^{(k)}}, M A_{R T P_{i, d, \max }^{(k)}} d=1, \ldots, D ; k=1,2
\end{gathered}
$$

where $\left(M A_{R T P_{i, d, \text { min }}}, M A_{R T P_{i, d, \text { max }}}\right)$ is the couple of $\min / \max M A R T P$ values in a daily period and $\left(M A_{R T P_{i, d, \text { min }}^{(k)}}, M A_{R T P_{i, d, \text { max }}^{(k)}}\right)$ is the couple of $\min / \max M A R T P$ values in the semi-daily period $k$ of the day $i$, respectively. The average values and the $\min / \max M A R T P$ values are calculated for each charge/discharge time $d$ and for each day $i$. The daily profile in Figure 3 corresponds to the RTP prices when $d=1$, to the $M A$ of $R T P$ prices when $d \neq 1$.

\subsection{Optimization Problem Formulation}

Since the battery can be charged once or twice a day, depending on the value of the objective function, the algorithm calculates the benefit for the storage owner (electricity customer) in both cases, verifying in which situation the objective function takes the maximum value. In the following sections, the objective function will be defined in both situations, by considering a daily or a semi-daily periodicity, respectively.
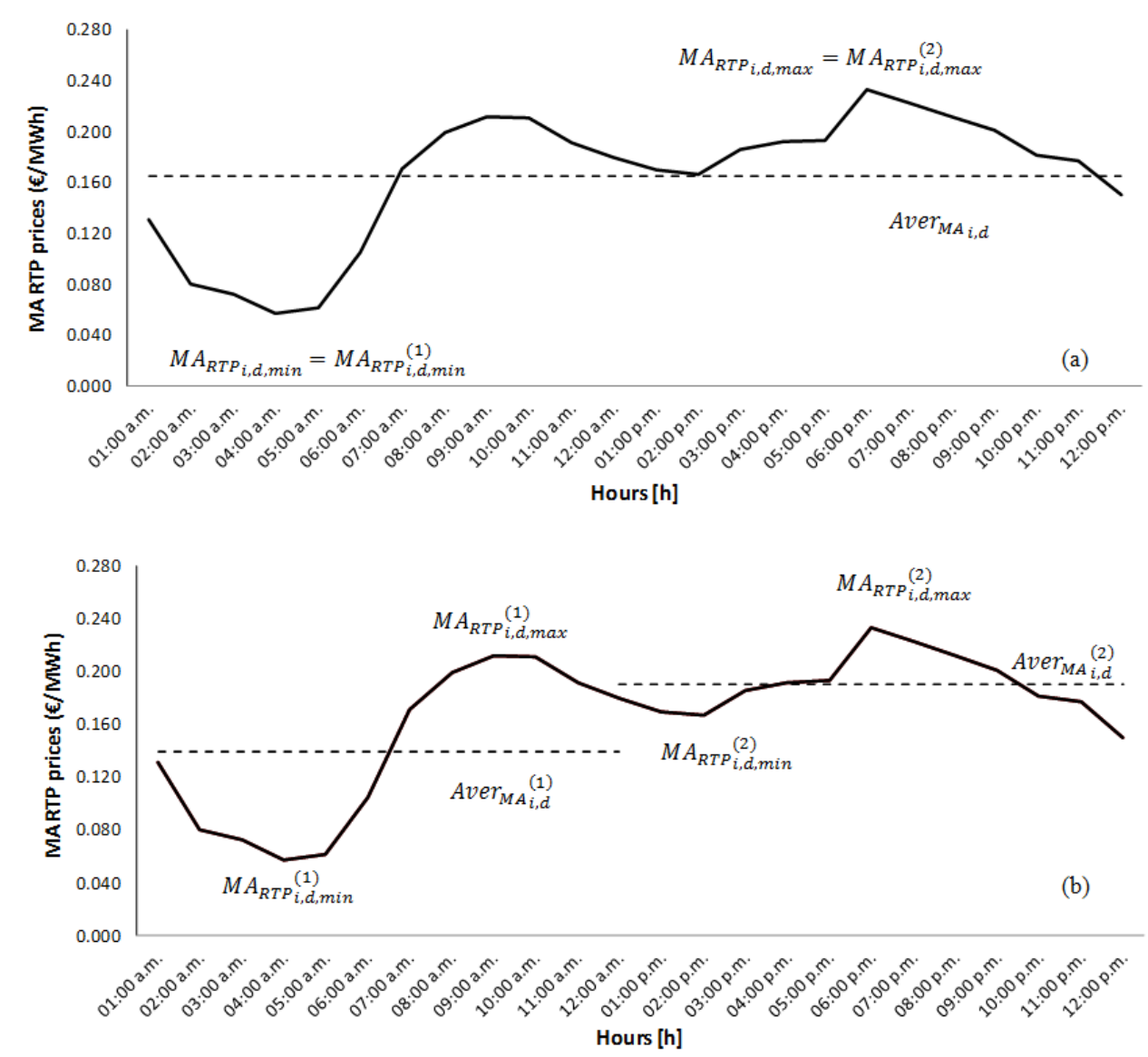

Figure 3. Daily profile of moving average of RTP prices (MA RTP) with daily average (a) and semi-daily average values (b). 


\subsubsection{Semi-Daily Periodicity}

Under the assumption of semi-daily periodicity, the storage device will perform two charging cycles per day, according to the MA RTP profile shown in Figure $3 \mathrm{~b}$. For each battery cycle, the problem comes down to maximizing the following objective function:

$$
O F_{i, d}^{(k)}=\max \left(S_{B E S S, i, d}^{(k)}-C_{B E S S_{c y c l e d, d}}\right)
$$

where $S_{B E S S, i, d}^{(k)}$ is the saving per $\mathrm{kWh}$ obtained charging/discharging the BESS over time $d$, in the semi-daily period $k$ of the day $i$ and $C_{B E S S_{\text {cycled, }}}$ is the storage cost per $\mathrm{kWh}$ cycled, obtained charging/discharging the BESS over time $d$.

The saving, $S_{B E S S, i, d}^{(k)}$ can be calculated as follows:

$$
S_{B E S S, i, d}^{(k)}=\frac{E_{B E S S, i, d}^{(k)}}{\operatorname{Cap}} \cdot\left(M A_{R T P_{i, d, \max }^{(k)}} \cdot \mu_{d}-\frac{M A_{R T P_{i, d, \min }^{(k)}}}{\mu_{c}}\right)=D O D \cdot\left(M A_{R T P_{i, d, \max }^{(k)}} \cdot \mu_{d}-\frac{M A_{R T P_{i, d, \min }^{(k)}}}{\mu_{c}}\right)
$$

where $E_{B E S S, i, d}^{(k)}$ is the energy discharged from the storage device over time $d$, and $\mu_{c}$ and $\mu_{d}$ are the charge/discharge efficiencies of the battery, respectively.

The storage cost per $\mathrm{kWh}$ cycled can be expressed as:

$$
C_{B E S S_{\text {cycled, }}}=\frac{C_{T O T_{B E S S}}}{\text { Cap } \cdot N_{\text {Full cycle,d }}}
$$

where $C_{T O T_{B E S S}}$ is the total cost of the storage and $N_{F u l l}$ cycle,d is the number of equivalent full cycles of the battery, corresponding to a charge/discharge time $d$.

Denoted by $C_{B E S S_{k W h}}$, the storage cost per kWh (from Equation (9)) can be expressed as:

$$
C_{B E S S_{\text {cycled,d }}}=\frac{C_{B E S S_{k W h}}}{N_{\text {Full cycle, }}}
$$

The objective function, $O F_{i, d}^{(k)}$, can finally be expressed as:

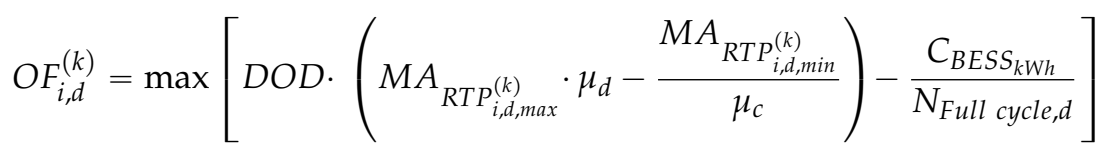

The only variable that appears in the objective function is the DOD. Indeed, $N_{\text {Full cycle,d }}$ and $\left(M A_{R T P_{i, d, \max }^{(k)}}, M A_{R T P_{i, d, \text { min }}^{(k)}}\right)$ are not independent variables, since they are linked to the DOD. The $D O D$ is thus the only variable to be optimized and the search space is the set of all possible charging/discharging times, namely all integers between 1 and $D$. Ultimately, the maximization of the objective function allows one to obtain the $D O D$ value that maximizes the customer's benefit, for each semi-daily charging/discharging cycle.

\subsubsection{Daily Periodicity}

In the same manner as was done in the previous section, in presence of a daily periodicity of the $M A R T P$ profile, the objective function, $O F_{i, d}$, can be expressed as:

$$
O F_{i, d}=\max \left[\operatorname{DOD} \cdot\left(M A_{R T P_{i, d, \max }} \cdot \mu_{d}-\frac{M A_{R T P_{i, d, m i n}}}{\mu_{c}}\right)-\frac{C_{B E S S_{k W h}}}{N_{\text {Full cycle, },}}\right]
$$


The maximization of the objective function allows one to obtain the $D O D$ value that maximizes the customer's benefit, for each daily charging/discharging cycle.

\subsubsection{Constraint Equations}

As already stated in Section 3, the battery charging and discharging constraints are automatically satisfied, since the charge/discharge rate of the battery is assumed constant. The storage energy constraints are also satisfied, since the battery returns to the same initial SOC at the end of each charge/discharge cycle (namely the energy discharged is equal to the energy charged, in each battery cycle). Furthermore, charging/discharging periods should not overlap each other. This might happen when the battery performs two operating cycles per day. If this is the case, the charging/discharging period will be reduced accordingly.

The charge/discharge cycle of the battery would only be worth it if the difference between the maximum and minimum values of MA RTP is higher than the cost of cycling energy plus the cost of the energy losses in the charge/discharge process. Expressed differently, Equations (11) and (12) must take positive values for the battery operation to be profitable:

$$
O F_{i, d}^{(k)}>0, O F_{i, d}>0
$$

If the constraints in Equation (13) are not satisfied, the battery will remain idle, since the arbitrage benefit is not enough to compensate for the cost of cycling energy plus the cost of the energy losses. In the following, the term "eligible" will be used to indicate an objective function whose value is greater than zero.

\subsubsection{Selection of the Charging/Discharging Intervals}

Once Equations (11) and (12) are calculated, the algorithm checks, for each day of the year, if the summation of the eligible objective functions corresponding to each semi-daily cycle is greater than that corresponding to the daily cycle, namely:

$$
\sum_{k=1}^{2} O F_{i, d}^{(k)} \geqslant O F_{i, d} d=1, \ldots, D
$$

If Equation (14) is satisfied, the battery is charged in the first half of the day, in the second half or in both, depending on the number of the eligible objective functions, $O F_{i, d}^{(k)}$. The DOD for each battery cycle is selected according to Equation (11). If Equation (14) is not satisfied, the battery will make only one cycle per day. The corresponding DOD is selected according to Equation (12). Finally, if all the objective functions have negative value (i.e., there are no eligible objective functions), the battery remains idle in the day $i$.

It is worth noting that the proposed operating strategy allows maximizing the customer's benefit under the assumptions described in Section 3. More complex and complete models could lead to higher benefits for the storage owner. Furthermore, the proposed method leads to an effective maximization of the objective function only if the SMP profile is assumed to have a convex form in the charging/discharging intervals, as in most spot electricity markets. If the price profile differs from a convex form, the proposed procedure could lead to suboptimal results, but it was verified that the error margin is narrow.

\section{Case Study}

The number of equivalent full cycles cannot be estimated directly, as it mainly depends on the energy cycled by the batteries, namely by the DOD. For most batteries, manufactures show in their datasheets the curves of number of cycles to failure, $N_{c y c l e, d}$ vs. the $D O D$ (for given temperature value), as shown in Figure 4, derived for a lead-acid battery [31]. 


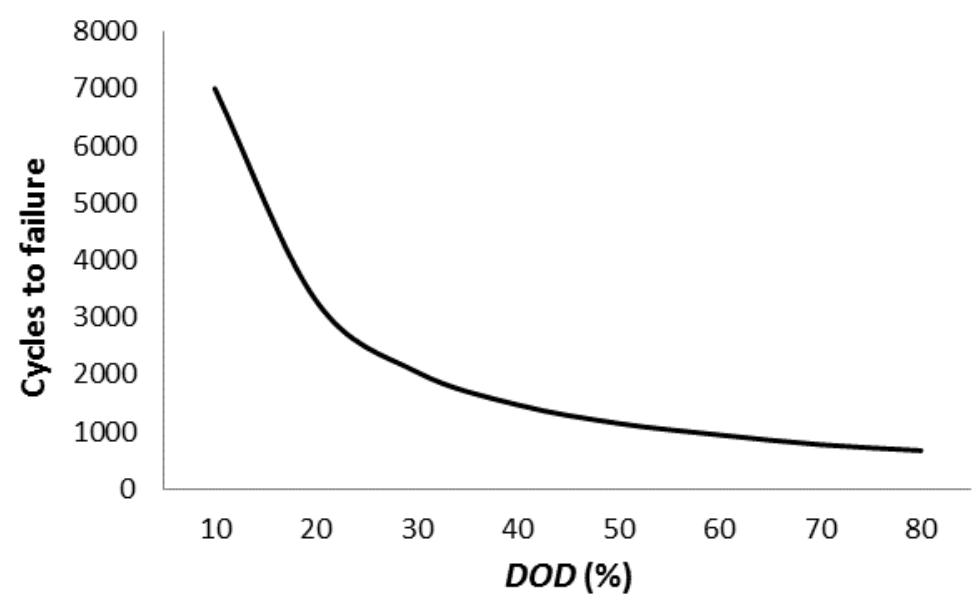

Figure 4. Typical cycles to failure vs. depth-of-discharge (DOD) curve for lead-acid-batteries.

The number of equivalent full cycles performed by the battery at a given $D O D$ can be obtained as [32]:

$$
N_{\text {Full cycle,d }}=D O D \cdot N_{\text {cycle,d }}
$$

where $N_{c y c l e, d}$ is the number of cycles to failure, as derived from Figure 4.

For most of electrochemical batteries, the number of equivalent full cycles remains constant (for given operating temperature) and does not depend on the DOD. Expressed differently, the total Ah a battery can deliver over its life is approximately constant. However, the relationship deviates for some electrochemistries, especially at low DOD. With a view to highlight the changes, Figure 5 shows a comparison of cycles to failure vs. DOD curves for three different BESS technologies (lead-acid, Li-ion and $\mathrm{NaS}$ battery).

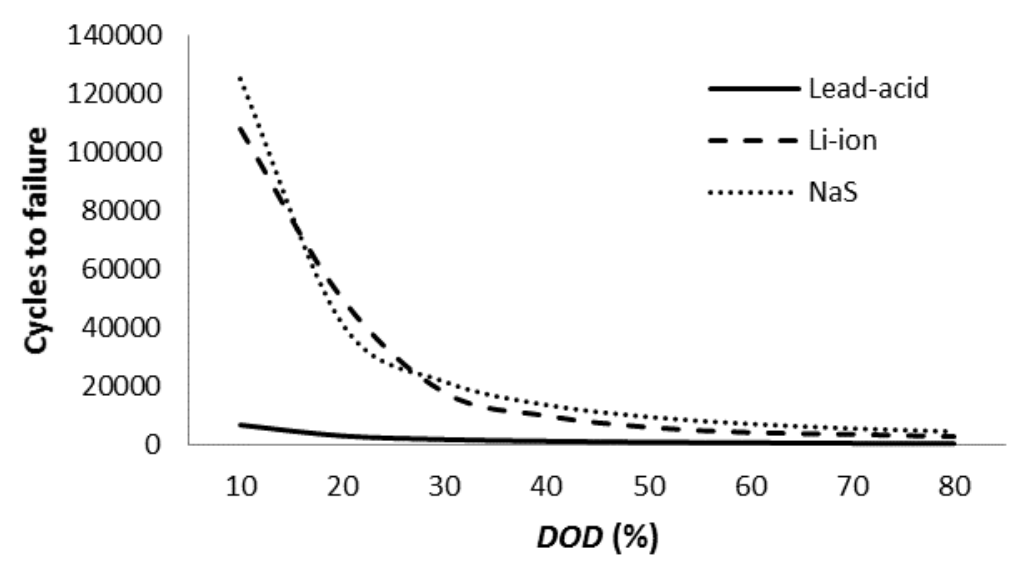

Figure 5. Cycles to failure vs. depth-of-discharge $(D O D)$ curve for three different battery technologies.

Let us assume $D_{\max }=5 \mathrm{~h}$, which corresponds to a discharging time $D=4 \mathrm{~h}$ at a $D O D=80 \%$. The number of equivalent full cycles, for each selected DOD (ranging from 1 to $4 \mathrm{~h}$ ), is reported in Table 1, for each of the selected battery technologies. The values were calculated using Equation (11). The number of cycles to failure, $N_{\text {cycles_ }}$, was deduced from the typical cycles to failure vs. $D O D$ curve, for each battery option $[31,33,34]$. Table 1 also shows the percentage increment, $\Delta N_{\text {Full }}(\%)$, with respect to the value corresponding to a $D O D=80 \%$. It is worth noting that the percentage increment is minimum for lead-acid, maximum for Li-ion battery. 
Table 1. Number of equivalent full cycles for each selected $D O D$, for the three battery technologies.

\begin{tabular}{ccccccc}
\hline & \multicolumn{2}{c}{ Lead-Acid Battery } & \multicolumn{2}{c}{ Li-Ion Battery } & \multicolumn{2}{c}{ NaS Battery } \\
\cline { 2 - 6 } $\boldsymbol{D O D}(\%)$ & $N_{\text {Full cycles,d }}$ & $\Delta N_{\text {Full }}(\%)$ & $N_{\text {Full cycles,d }}$ & $\Delta N_{\text {Full }}(\%)$ & $N_{\text {Full cycles,d }}$ & $\Delta N_{\text {Full }}(\%)$ \\
\hline $80 \%$ & 540 & & 2400 & & 3592 & \\
$60 \%$ & 570 & 5.56 & 2640 & 10 & 4269 & 18.85 \\
$40 \%$ & 590 & 9.26 & 4040 & 68.3 & 5445 & 51.58 \\
$20 \%$ & 660 & 22.22 & 10000 & 316.7 & 8253 & 129.76 \\
\hline
\end{tabular}

The analysis has been carried out by referring to a typical medium-scale public facility (Department of Energy, Information engineering and Mathematical models (DEIM), University of Palermo). For the selected facility, a reference weekly period has been considered, from 31 March to 6 April 2014. The SMP for the reference weekly period have already been reported in Figure 2.

The proposed strategy can be applied to several kinds of storages, but the test results refer to three kind of batteries, lead-acid, Li-ion and NaS, that are, nowadays, the most suitable to be used in residential, commercial or industrial buildings, for load shifting applications. Among the three technologies, Li-ion batteries are the most promising in terms of cost reduction and cycling performance [35]. The technical and economic parameters are reported in Table 2 for each of the selected battery technologies.

Table 2. Technical and economic parameters selected for the three battery technologies.

\begin{tabular}{cccc}
\hline Components & \multicolumn{3}{c}{ Specifications } \\
\hline Technology & Lead-Acid Battery & Li-Ion Battery & NaS Battery \\
\hline Energy capacity $(\mathrm{kWh})$ & 20 & 20 & 20 \\
Power rating $(\mathrm{kW})$ & 5 & 5 & 5 \\
Roundtrip efficiency $(\%)$ & 82 & 90 & 81 \\
Operating temperature $\left({ }^{\circ} \mathrm{C}\right)$ & $(-20)-(+50)$ & $(-20)-(+45 /+60)$ & $300-350$ \\
Healthy DOD $(\%)$ & 80 & 80 & NA \\
Cycles to failure $(80 \% D O D)$ & 1100 & 3000 & 4500 \\
BESS cost $(€ / \mathrm{kWh})$ & 171 & 844 & 256 \\
PCS cost $(€ / \mathrm{kW})$ & 172 & 125 & 171 \\
BOP cost $(€ / \mathrm{kW})$ & 70 & 0 & 53 \\
\hline
\end{tabular}

The storage cost and the charge/discharge roundtrip efficiency have been selected calculating the arithmetic mean between low and high literature values [36]. In Table 2, the total storage cost has been decomposed as the sum of the power conversion system (PCS) cost, the BESS cost and the balance-of plant (BOP) cost [37]. The operating temperatures and the healthy $D O D$ were derived from [29]. The rated energy capacity (equal to $20 \mathrm{kWh}$ for each battery) was selected referring to the facility's energy consumption during peak price hours, on the day of the year of lowest consumption, as already specified in Section 3.

The storage costs per kWh cycled are on average higher than the difference between maximum and minimum electricity prices. Indeed, the average storage costs per $\mathrm{kWh}$ cycled are equal to $0.171 € / \mathrm{kWh}$ cycled for lead-acid, $0.103 € / \mathrm{kWh}$ cycled for Li-ion and $0.096 € / \mathrm{kWh}$ cycled for $\mathrm{NaS}$ batteries, as against a maximum value of $0.1 € / \mathrm{kWh}$ for the difference between maximum and minimum electricity price. For this reason, a grant equal to $75 \%$ of the upfront investment cost is considered in this analysis. The storage costs per $\mathrm{kWh}$ cycled have been obtained considering average values of $C_{B E S S_{k W h}}$ and $N_{\text {Full cycle, }}$ according to [36]. 


\section{Simulation Results}

For each day of the reference period, the algorithm handles the MA RTP prices, corresponding to each $D O D$, calculating the value of the objective functions and verifying the fulfillment of condition in Equation (14).

The values of the objective functions together with the charge/discharge time, for the three battery technologies, are reported in Table 3. If Equation (14) is satisfied, Table 3 reports the value of $\sum_{k=1}^{2} O F_{i, d}^{(k)}$ and the column $d$ shows a couple of values, $(x, y)$, denoting the charging/discharging time of the first and the second half day period, respectively. If Equation (14) is not satisfied, the value of the daily objective function, $O F_{i, d}$, is reported and the column $d$ shows a single value denoting the charging/discharging time in the daily period. Finally, if all the objective functions have negative value (i.e., there are no eligible objective functions) the battery remains idle and the corresponding values of the objective function and the charging/discharging times are missing in Table 3.

Table 3. Values of the objective functions in the reference weekly period.

\begin{tabular}{lcccccc}
\hline & \multicolumn{2}{c}{ Lead Acid } & \multicolumn{2}{c}{ Li-ion } & \multicolumn{2}{c}{ NaS } \\
\cline { 2 - 7 } & OF & $\boldsymbol{d}$ & OF & $\boldsymbol{d}$ & OF & $\boldsymbol{d}$ \\
\hline $31 / 03 / 2014$ & 0.038 & 4,4 & 0.036 & 2,1 & 0.122 & 4,4 \\
$01 / 04 / 2014$ & - & - & - & - & 0.049 & 4,4 \\
$02 / 04 / 2014$ & - & - & 0.002 &,- 1 & 0.047 & 4,3 \\
$03 / 04 / 2014$ & - & - & - & - & 0.018 & 3,2 \\
$04 / 04 / 2014$ & - & - & 0.004 & $1,-$ & 0.042 & $4,-$ \\
$05 / 04 / 2014$ & - & - & 0.001 & 1 & 0.043 & 4,4 \\
$06 / 04 / 2014$ & 0.028 &,- 4 & 0.01 &,- 4 & 0.071 &,- 4 \\
Weekly OF & 0.066 & & 0.053 & & 0.392 & \\
\hline
\end{tabular}

The values reported in Table 3 lead to the following fundamental results (valid under the assumption that a subsidy equal to $75 \%$ of the upfront investment cost is granted to the storage owner):

- Among the three considered storage options, the use of $\mathrm{NaS}$ batteries leads to the maximum benefit for the storage owner (the value of the weekly objective function is around six times the one observed for the lead-acid battery); indeed, although NaS batteries have an acquisition cost higher than lead-acid, the number of cycles to failure is more than three times higher than that of lead-acid battery (see Table 2).

- The lead-acid technology appears to be the least convenient for arbitrage applications, despite its lower cost. This is essentially due to the low number of equivalent full cycles compared to the other battery technologies. The Li-ion technology also has a low profitability for arbitrage applications, essentially because of the high upfront investment cost. However, the situation could rapidly change since Li-ion batteries are the most promising in terms of cost reduction and cycling performance [31].

- Lead-acid battery remains idle during most of the days, since the gap between maximum and minimum electricity price is not enough to compensate for the low number of equivalent full cycles.

- As previously stated in Section 4.1, NaS battery is charged two times per day on weekdays (except on Friday), and only one time on Sunday. This is because weekdays have two price peeks, and the gap between $\mathrm{max} / \mathrm{min}$ electricity price is high enough to compensate for the cost of cycling energy plus the cost of the energy losses in the charge/discharge process.

- The NaS battery often performs two operating cycles, whereas the Li-ion battery performs two operating cycles only on Monday. This is essentially due to the high upfront investment cost of Li-ion battery compared with $\mathrm{NaS}$ technology, and to the lower number of equivalent full cycles. 
- On Sunday, the batteries perform only one cycle in the second half of the day, lasting four hours (as previously stated in Section 4.1).

It is worth noting that the battery cycle lasts four hours when the objective function takes a high value, i.e., when the gap between high and low electricity prices is large. Indeed, in this case the first term of the objective function prevails over the second term and the higher $D O D$ resulting from the greater discharge duration offsets the number of equivalent full cycles.

Finally, it is possible to assert that, at the current price of storage technologies, the use of batteries for arbitrage applications is not profitable for the storage owner. The battery is charged once a day or twice a day depending on the shape of RTP profiles, being the BESS operating cycle dependent on the specific battery technology.

In order to highlight the advantages of the proposed approach compared to other simple methods, a comparison is made with respect to a simple strategy (base case) where the battery is operated in the hours where the gap between the lowest and the highest prices is maximized. The base case differs from the proposed operating strategy since the battery can be operated at different hours, not necessarily uninterrupted, but always regardless of the facility's load profile. Besides, in the base case, the battery is operated always at its maximum $D O D(4 \mathrm{~h})$, if the discharge duration is compatible with the objective function values, under the fulfillment of constraint conditions.

The values of the objective functions together with the charge/discharge time, in the base case, are shown in Table 4 . When the objective functions have negative value, the corresponding values and the charging/discharging times are missing in Table 4.

Table 4. Values of the objective functions for the base case.

\begin{tabular}{ccccccc}
\hline & \multicolumn{2}{c}{ Lead acid } & \multicolumn{2}{c}{ Li-ion } & \multicolumn{2}{c}{ NaS } \\
\cline { 2 - 7 } & OF & $d$ & OF & $d$ & OF & $d$ \\
\hline $31 / 03 / 2014$ & 0.038 & 4,4 & 0.014 & 4,4 & 0.122 & 4,4 \\
$01 / 04 / 2014$ & - & - & - & - & 0.049 & 4,4 \\
$02 / 04 / 2014$ & - & - & - & - & 0.046 & 4,4 \\
$03 / 04 / 2014$ & - & - & - & - & 0.013 & 4,4 \\
$04 / 04 / 2014$ & - & - & - & - & 0.042 & $4,-$ \\
$05 / 04 / 2014$ & - & - & - & - & 0.043 & 4,4 \\
$06 / 04 / 2014$ & 0.028 &,- 4 & 0.009 &,- 4 & 0.071 &,- 4 \\
Weekly OF & 0.066 & & 0.023 & & 0.386 & \\
$\%$ weekly increase & - & & $130 \%$ & & $1.5 \%$ & \\
\hline
\end{tabular}

It was found that the percentage increase of the weekly objective function, compared to the base case, is $130 \%$ for $\mathrm{Li}$-ion and $1.5 \%$ for NaS batteries, as reported in Table 4.

According to the values reported in Table 4, the comparison between the proposed operating strategy and the base case leads to the following considerations:

- For lead acid battery, the values of the objective function are the same (the weekly percentage increase is zero). Indeed, this kind of battery performs the same charging/discharging cycles both in the proposed operating strategy and in the base case.

- For Li-ion battery, the weekly percentage increase of the objective function is large $(130 \%)$. Indeed, in the base case the Li-ion battery remains idle for most of the days and the value of the objective function on Monday is more than halved compared with the corresponding value reported in Table 3.

- For NaS battery, the weekly percentage increase of the objective function is $1.5 \%$, as a result of an increase of the objective functions on Wednesday and Thursday.

The last conclusion is particularly meaningful since it confirms that operating the battery at low $D O D$ can be advantageous for the storage owner when the gap between high and low electricity prices is limited (e.g., when the objective function takes a small value). 
Figure $6 \mathrm{a}, \mathrm{b}$ show the graphic comparison between the objective function values of the two approaches, for $\mathrm{NaS}$ and Li-ion battery, respectively.

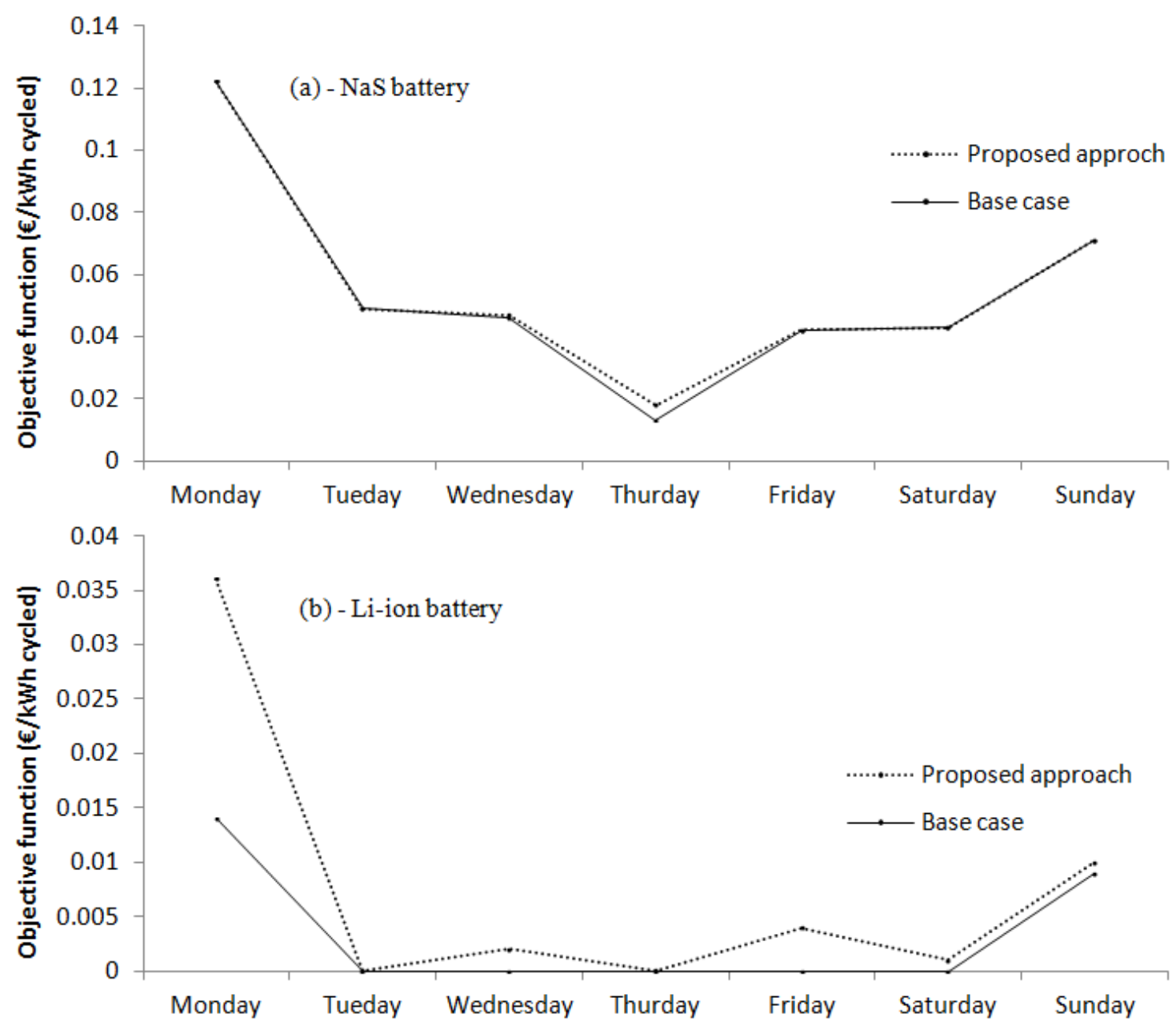

Figure 6. Graphic comparison between the objective function values of the two approaches: (a) NaS battery and (b) Li-ion battery.

The results obtained from the proposed approach show the effectiveness of the proposed operating strategy compared to the base case.

Finally, the effect of the proposed operating strategy on the daily curve of the energy extracted from the main grid is evaluated. To this aim, the power consumption of the department was registered over a reference period of one week (from 31 March to 6 April 2014).

Figure 7 shows the DEIM power diagram for the reference period, without (Figure 7a) and with (Figure $7 \mathrm{~b}$ ) storage contribution. 

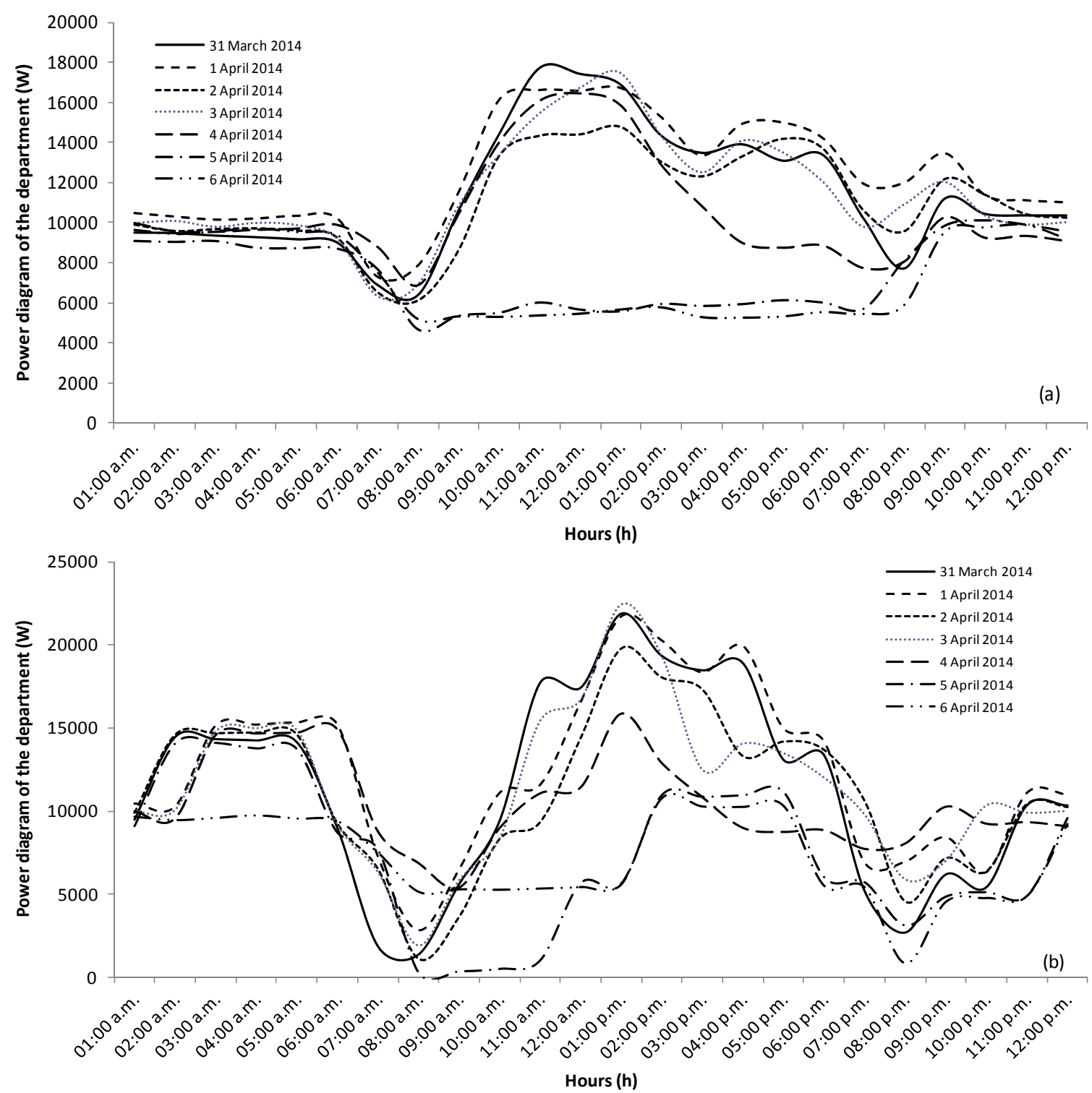

Figure 7. Power diagram of the department without (a) and with storage contribution (b).

Figure $7 \mathrm{~b}$ shows power spikes due to the BESS charging/discharging. The maximum weekly peak load is increased at $23 \mathrm{~kW}$ (against a value of $18 \mathrm{~kW}$ without storage) when the proposed operating strategy is applied. Conversely, the minimum weekly peak load is reduced to zero when the storage is operated (against a value of $5 \mathrm{~kW}$ without storage). Therefore, the implementation of the proposed strategy does not lead to a flattening of the power profile but to an increase in the gap between peak and off-peak loads.

\section{Conclusions and Future Work}

This paper develops a detailed storage model linking together technical, economic and electricity market parameters. The storage system is described by means of its performance parameters, such as the charge and generate capacity, the charge/discharge efficiency, the rated charge/discharge rate, the $D O D$, etc., which are sufficient to evaluate the arbitrage potential of the storage device. The proposed operating strategy aims to maximize the profit of the storage owner (electricity customer) by determining the optimal charge/discharge schedule. Unlike the studies reported in the literature, often requiring an estimate of the end-user load profile, the proposed operating strategy is able to 
identify the proper charging schedule of the device regardless of the specific facility's consumption. This is made possible since the battery is sized referring to the facilities' energy consumption during peak price hours, on the day of the year of lowest consumption. Under this assumption, the storage will be able to supply the entire customer load during the day of the year of lowest consumption, but only a portion of the customer's load on the other days. This could be particularly useful when the customer load profile cannot be scheduled with sufficient reliability, because of the uncertainty inherent in load forecasting. In these cases, identifying a BESS operating strategy that does not depend on the user's power profile can be an important task, since the deviation of the scheduled power profile from the effective one could affect the results obtained using more complete methods. In order to highlight the advantages of the proposed approach compared to other methods, a comparison is made with respect to a simple strategy (base case) where the battery is charged only one time per day at its maximum $D O D$ (equal to four hours). The results obtained from the proposed approach show the effectiveness of the proposed operating strategy. The proposed model can be applied to several kinds of storages but the test results refer to three electrochemical technologies: lead-acid, Li-ion and NaS battery. The simulation results show that the operating schedule of the storage device differs in the various days of the week and it depends on the specific battery used (the most critical parameters being the acquisition cost of the battery bank and the number of cycles to failure). The operating cycle lasts four hours (i.e., the maximum available charge/discharge time) when the objective function takes high values. However, in the days when the objective function has a lower value, the storage device is operated at a lower discharging time. This is because the higher gap between high and low electricity prices and the higher value of equivalent full cycles fully offset the less benefit due to the lower $D O D$ (which results in a lower energy discharged). Simulation results show that, at current prices, no BESS technology is cost effective, due to the high upfront investment costs. However, if a subsidy is granted to reduce the initial investment cost, the use of $\mathrm{NaS}$ batteries leads to the maximum benefit among the three considered storage options. This is essentially due to the high number of equivalent full cycles (four times higher than that of lead-acid batteries). Conversely, the lead-acid technology appears to be the least convenient for arbitrage applications, despite its lower cost. This is essentially due to the low number of equivalent full cycles compared to the other battery technologies. In addition, the Li-ion technology has a low profitability for arbitrage applications, essentially because of the high upfront investment cost. However, the situation could rapidly change since Li-ion batteries are the most promising in terms of cost reduction and cycling performance.

In a future work, the authors will evaluate the effect of load forecasting uncertainty on the accuracy of storage operating strategies, in order to demonstrate that often the deviation of the scheduled power profile from the effective one could affect the results of more complete methods.

Acknowledgments: This work was supported by the project i-NEXT (Innovation for greeN Energy and eXchange in Transportation), identification code: PON04a2_Hi-NEXT (CUP B71H12000700005).

Author Contributions: This work was conceived by Enrico Telaretti. Preparation of the manuscript has been performed by Enrico Telaretti. Simulation and analysis of the results have been perfomed by Enrico Telaretti. Luigi Dusonchet and Mariano Ippolito supervised the work, giving a final review of the paper. All authors read and agreed to the final article.

Conflicts of Interest: The authors declare no conflict of interest. 


\section{Abbreviations}

$\begin{array}{ll}\text { BESS } & \text { Battery Energy Storage System } \\ \text { BOP } & \text { Balance-of Plant } \\ \text { DEIM } & \text { Department of Energy, Information Engineering and Mathematical Models } \\ \text { DOD } & \text { Depth-of-Discharge } \\ \text { DSM } & \text { Demand Side Management } \\ \text { IRR } & \text { Internal Rate of Return } \\ \text { Li-ion } & \text { Lithium-Ion } \\ \text { MA } & \text { Moving Average } \\ \text { MA RTP } & \text { Moving Average of RTP Prices } \\ \text { NaS } & \text { Sodium-Sulphur } \\ \text { PCS } & \text { Power Conversion System } \\ \text { PSO } & \text { Particle Swarm Optimization } \\ \text { PV } & \text { Photovoltaic } \\ \text { RES } & \text { Renewable Energy Sources } \\ \text { RTP } & \text { Real-Time Pricing } \\ \text { SMP } & \text { System Marginal Price } \\ \text { SOC } & \text { State-of-Charge } \\ \text { TOU } & \text { Time-of-Use } \\ \text { VAT } & \text { Value Added Tax }\end{array}$

\section{References}

1. Campoccia, A.; Dusonchet, L.; Telaretti, E.; Zizzo, G. Feed-in tariffs for grid-connected PV systems: The situation in the European community. In Proceedings of IEEE Power Tech Conference, Lausanne, Switzerland, 1-5 July 2007; pp. 1981-1986.

2. Campoccia, A.; Dusonchet, L.; Telaretti, E.; Zizzo, Z. Financial Measures for Supporting Wind Power Systems in Europe: A Comparison between Green Tags and Feed'in Tariffs. In Proceedings of IEEE Power Electronics, Electrical Drives, Automation and Motion, Ischia, Italy, 11-13 June 2008; pp. 1149-1154.

3. Sgroi, F.; Tudisca, S.; Di Trapani, A.M.; Testa, R.; Squatrito, R. Efficacy and Efficiency of Italian Energy Policy: The Case of PV Systems in Greenhouse Farms. Energies 2014, 7, 3985-4001. [CrossRef]

4. Giannini, E.; Moropoulou, A.; Maroulis, Z.; Siouti, G. Penetration of Photovoltaics in Greece. Energies 2015, 8, 6497-6508. [CrossRef]

5. Borenstein, S. The long-run efficiency of real-time electricity pricing. Energy J. 2005, 26, 93-116. [CrossRef]

6. Dusonchet, L.; Ippolito, M.G.; Telaretti, E.; Graditi, G. Economic impact of medium-scale battery storage systems in presence of flexible electricity tariffs for end-user applications. In Proceedings of IEEE International Conference on the European Energy Market, Florence, Italy, 10-12 May 2012; pp. 1-5.

7. Dusonchet, L.; Ippolito, M.G.; Telaretti, E.; Zizzo, G.; Graditi, G. An optimal operating strategy for combined RES-based Generators and Electric Storage Systems for load shifting applications. In Proceedings of IEEE International Conference on Power Engineering, Energy and Electrical Drives, Instanbul, Turkey, 13-17 May 2013; pp. 552-557.

8. Youn, L.T.; Cho, S. Optimal operation of energy storage using linear programming technique. In Proceedings of the World Congress on Engineering and Computer Science, San Francisco, CA, USA, 20-22 October 2009; pp. 480-485.

9. Ahlert, K.; Van Dinther, C. Sensitivity analysis of the economic benefits from electricity storage at the end consumer level. In Proceedings of IEEE Power Tech Conference, Bucharest, Romania, 28 June-2 July 2009; pp. 1-8.

10. Bradbury, K.; Pratson, L.; Patino-Echeverri, D. Economic viability of energy storage systems based on price arbitrage potential in real-time U.S. electricity markets. Appl. Energy 2014, 114, 512-519. [CrossRef]

11. Graves, F.; Jenkin, T.; Murphy, D. Opportunities for Electricity Storage in Deregulating Markets. Electr. J. 1999, 12, 46-56. [CrossRef] 
12. Hu, W.; Chen, Z.; Bak-Jensen, B. Optimal operation strategy of battery energy storage system to real-time electricity price in Denmark. In Proceedings of the IEEE Power and Energy Society General Meeting, Minneapolis, MN, USA, 25-29 July 2010; pp. 1-7.

13. Mokrian, P.; Stephen, M. A stochastic programming framework for the valuation of electricity storage. In Proceedings of 26th USAEE/IAEE North American Conference, Ann Arbor, MI, USA, 24-27 September 2006; pp. 1-34.

14. Maly, D.K.; Kwan, K.S. Optimal battery energy storage system (BESS) charge scheduling with dynamic programming. IEE Proc. Sci. Meas. Technol. 1995, 142, 454-458. [CrossRef]

15. Van de Ven, P.M.; Hegde, N.; Massoulié, L.; Salonidis, T. Optimal control of residential energy storage under price fluctuations. In Proceedings of International Conference on Smart Grids, Green Communications and IT Energy-aware Technologies, Venice, Italy, 22-27 May 2011; pp. 159-162.

16. Huang, T.; Liu, D. Residential energy system control and management using adaptive dynamic programming. In Proceedings of the International Joint Conference on Neural Networks, San Jose, CA, USA, 31 July-5 August 2011; pp. 119-124.

17. Lee, T.Y. Operating Schedule of Battery Energy Storage System in a Time-of-Use Rate Industrial User With Wind Turbine Generators: A Multipass Iteration Particle Swarm Optimization Approach. IEEE Trans. Energy Conv. 2007, 22, 774-782. [CrossRef]

18. Abeygunawardana, A.; Ledwich, G. Estimating benefits of energy storage for aggregate storage applications in electricity distribution networks in Queensland. In IEEE Power and Energy Society General Meeting, Vancouver, BC, Canada, 21-25 July 2013; pp. 1-5.

19. Byrne, C.; Verbic, G. Feasibility of Residential Battery Storage for Energy Arbitrage. In Proceedings of Power Engineering Conference (AUPEC), 2013 Australasian Universities, Hobart, TAS, Australia, 29 September-3 October 2013; pp. 1-7.

20. Ekman, C.K.; Jensen, S.H. Prospects for large scale electricity storage in Denmark. Energy Convers. Manag. 2010, 51, 1140-1147. [CrossRef]

21. Shcherbakova, A.; Kleit, A.; Cho, J. The value of energy storage in South Korea's electricity market: a Hotelling approach. Appl. Energy 2014, 125, 93-102. [CrossRef]

22. Purvins, A.; Sumner, M. Optimal management of stationary lithium-ion battery system in electricity distribution grids. J. Power Sources 2013, 242, 742-755. [CrossRef]

23. Castillo-Cagigal, M.; Caamaño-Martín, E.; Matallanas, E.; Masa-Bote, D.; Gutiérrez, A.; Monasterio-Huelin, F.; Jiménez-Leube, J. PV self-consumption optimization with storage and Active DSM for the residential sector. Sol. Energy 2011, 85, 2338-2348. [CrossRef]

24. Matallanas, E.; Castillo-Cagigal, M.; Gutiérrez, A.; Monasterio-Huelin, F.; Caamaño-Martín, E.; Masa, D.; Jiménez-Leube, J. Neural network controller for Active Demand-Side Management with PV energy in the residential sector. Appl. Energy 2012, 91, 90-97. [CrossRef]

25. Abushnaf, J.; Rassau, A.; Górnisiewicz, W. Impact of dynamic energy pricing schemes on a novel multi-user home energy management system. Electr. Power Syst. Res. 2015, 125, 124-132. [CrossRef]

26. Ippolito, M.G.; Telaretti, E.; Zizzo, G.; Graditi, G.; Fiorino, M. A Bidirectional Converter for the Integration of $\mathrm{LiFePO}_{4}$ Batteries with RES-based Generators. Part I: Revising and finalizing design. In Proceedings of 3rd Renewable Power Generation Conference, Naples, Italy, 24-25 September 2014; pp. 1-6.

27. Ippolito, M.G.; Telaretti, E.; Zizzo, G.; Graditi, G.; Fiorino, M. A Bidirectional Converter for the Integration of $\mathrm{LiFePO}_{4}$ Batteries with RES-based Generators. Part II: Laboratory and Field Tests. In Proceedings of 3rd Renew. Power Generation Conference, Naples, Italy, 24-25 September 2014; pp. 1-6.

28. Viera, J.C.; Gonzalez, M.; Liaw, B.Y.; Ferrero, F.J.; Alvarez, J.C.; Campo, J.C.; Blanco, C. Characterization of $109 \mathrm{Ah}$ Ni-MH batteries charging with hydrogen sensing termination. J. Power Sources 2007, 171, 1040-1045. [CrossRef]

29. Zheng, M.; Meinrenken, C.J.; Lackner, K.S. Agent-based model for electricity consumption and storage to evaluate economic viability of tariff arbitrage for residential sector demand response. Appl. Energy 2014, 126, 297-306. [CrossRef]

30. GME home page. Available online: http://www.mercatoelettrico.org/it/Default.aspx (accessed on 26 May 2015).

31. Dufo-López, R. Optimisation of size and control of grid-connected storage under real time electricity pricing conditions. Appl. Energy 2015, 140, 395-408. [CrossRef] 
32. Dufo-López, R.; Bernal-Agustin, J.L. Techno-economic analysis of grid-connected battery storage. Energy Conv. Manag. 2015, 91, 394-404. [CrossRef]

33. The Lithium-Ion Battery. Service Life Parameters. Available online: https://www2.unece.org/wiki/ download/attachments/8126481/EVE-06-05e.pdf?api=v2 (accessed on 26 May 2015).

34. Lu, N.; Weimar, M.R.; Makarov, Y.V.; Ma, J.; Viswanathan, V.V. The Wide-Area Energy Storage and Management System-Battery Storage Evaluation. Available online: http://www.pnl.gov/main/ publications/external/technical_reports/PNNL-18679.pdf (accessed on 26 May 2015).

35. Divya, K.C.; Østergaard, J. Battery energy storage technology for power systems-An Overview. Electr. Power Syst. Res. 2009, 79, 511-520. [CrossRef]

36. Battke, B.; Schmidt, T.S.; Grosspietsch, D.; Hoffmann, V.H. A review and probabilistic model of life cycle costs of stationary batteries in multiple applications. Renew. Sustain. Energy Rev. 2013, 25, 240-250. [CrossRef]

37. Telaretti, E.; Sanseverino, E.R.; Ippolito, M.; Favuzza, S.; Zizzo, G. A novel operating strategy for customer-side energy storages in presence of dynamic electricity prices. Intell. Ind. Syst. 2015, 1, 233-244. [CrossRef]

(C) 2015 by the authors; licensee MDPI, Basel, Switzerland. This article is an open access article distributed under the terms and conditions of the Creative Commons by Attribution (CC-BY) license (http://creativecommons.org/licenses/by/4.0/). 